\title{
Redução do número de empreendimentos agrícolas no Brasil
}

\author{
A decline in number of farms in Brazil \\ Tiago Santos Telles ${ }^{1}$ (D), Gustavo Henrique Leite de Castro $^{2}$ (D), Thiago Luiz Ragugnetti Furlaneto ${ }^{3}$ (D), \\ Gustavo Vaz da Costa ${ }^{3}$ (i) \\ 1Instituto de Desenvolvimento Rural do Paraná - IAPAR-EMATER, Londrina (PR), Brasil. E-mail: telles@idr.pr.gov.br \\ 2Programa de Pós-graduação em Economia, Universidade de São Paulo (USP), São Paulo (SP), Brasil. E-mail: gustavocastro@usp.br \\ 3Programa de Pós-graduação em Agronomia, Universidade Estadual de Londrina (UEL), Londrina (PR), Brasil. E-mails: \\ thiagofurlaneto@yahoo.com.br; gustavo.vaz.costa@gmail.com
}

\begin{abstract}
Como citar: Telles, T. S., Castro, G. H. L., Furlaneto, T. L. R., \& Costa, G. V. (2022). Redução do número de empreendimentos agrícolas no Brasil. Revista de Economia e Sociologia Rural, 60(spe), e248645. https://doi. org/10.1590/1806-9479.2021.248645
\end{abstract}

\begin{abstract}
Resumo: Questões relacionadas aos empreendimentos agrícolas vêm sendo discutidas em todo o mundo, o que ocorre pela importância deles no desenvolvimento econômico das nações, por estarem diretamente relacionados às transformações sociais dentro e fora do campo e por serem imprescindíveis para a produção e a oferta de alimentos, bem como para a segurança alimentar. Neste contexto, o objetivo deste estudo foi caracterizar as tendências de variação no número de empreendimentos agrícolas no Brasil, por tipo de atividade principal e por estrato de área, para o período de 2004 a 2015. Para tanto, foram utilizados dados da Pesquisa Nacional por Amostra de Domicílios e calculadas as taxas médias de variação anual, por meio do teste $t$ de Student, utilizando uma regressão dos mínimos quadrados ordinários na forma log-linear Entre 2004 e 2015, foi constatada queda de 3,3\% a.a. no número de empreendimentos agropecuários no Brasil, totalizando uma redução de 1.382.700 unidades produtivas. Também foi observado que as reduções mais intensas ocorreram nos empreendimentos agrícolas dedicados à produção de arroz (-13,4\% a.a.), nos de lavouras temporárias (-12,5\% a.a.) e naqueles com área de $\geq 50$ a $<100$ hectares $(-4,5 \%$ a.a.) Tais constatações são relevantes e permitem o delineamento de ações voltadas à segurança alimentar e nutricional no Brasil.
\end{abstract}

Palavras-chave: PNAD, empregador, conta própria, atividade agrícola, estrato de área.

Abstract: Issues related to farms have been discussed in a global context due to their importance in the process of economic development. This is because they have direct impacts on social transformations inside and outside the field, besides being an important part of the system of ensuring the supply and food security of the population. Thereby, this study aimed to characterize the trends of variation in the number of farms in Brazil, by the type of main activity, and by farm size, from 2004 to 2015 . For that, we used data from the National Households Sample Survey (NHSS) and the average rates of annual variation were calculated by Student's t-test using a log-linear least squares regression. From the results, there was a reduction of 3.3\% per year in the farms in Brazil, a total decrease of 1,382,700 farms in the evaluated period. There was an intense drop in farms dedicated to rice (-13.4\% per year) and temporary crops (-12.5\% per year) and in those from $\geq 50$ ha to $<100$ ha (-4.5\% per year). This information may subsidize the outlining of actions directed to food and nutritional security in Brazil.

Keywords: NHSS, employer, self-employed, agricultural activity, farm size.

\section{INTRODUÇÃO}

O meio rural brasileiro passou por profundas transformações, iniciadas em meados da década de 1960 com o processo de modernização da agricultura, impulsionado pelo pacote tecnológico da revolução verde. Como consequência, entre 1970 e 2010, o percentual de brasileiros que viviam no meio rural caiu significativamente, de $44 \%$ para 15,6\% da população total do país (Maia \& Buainain, 2015). Essa tendência de declínio acarretou, especialmente 
a partir dos anos 2000, o interesse em se analisar as dinâmicas populacionais referentes às pessoas ocupadas no meio rural brasileiro (Neder, 2008; Buainain \& Dedecca, 2010; Proni, 2010; Sakamoto \& Maia, 2012; Staduto et al., 2013; Mattei, 2015; Laurenti et al., 2015; Balsadi \& Del Grossi, 2016). De modo geral, houve redução da população economicamente ativa (PEA) ocupada em atividades agrícolas e um aumento da PEA rural ocupada em atividades não agrícolas. A principal justificativa para essa dinâmica, relacionada à PEA agrícola, continua sendo a modernização da agricultura, que leva a alterações no modo de produção, com destaque para a mecanização da produção, com tecnologias poupadoras de mão de obra, exigindo, cada vez mais, pessoas com melhor qualificação para os postos de ocupação (Ferreira et al., 2006; Del Grossi \& Graziano da Silva, 2006). A continuidade desse processo ocorre porque apenas uma parcela dos agentes é capaz de incorporar e absorver o conteúdo tecnológico, enquanto a outra fica à margem, não somente do ambiente organizacional inovador, mas também dos processos de aprendizado e de difusão das novas técnicas e conhecimentos produtivos (Vieira Filho, 2013).

Assim, de forma geral, a adoção de novas tecnologias no Brasil tende a colocar em desvantagem os produtores menos capitalizados. Com isso, as desigualdades nos processos produtivos podem levar à exclusão de parcela dos produtores rurais, sobretudo daqueles mais vulneráveis, cujas atividades agropecuárias estão relacionadas à produção de alimentos básicos, e, especialmente, dos que estão em áreas não mecanizáveis. Como resultado, a produção agrícola, em particular a produção de grãos, tem se tornado cada vez menos diversificada e cada vez mais concentrada em grandes áreas (Helfand et al., 2014; Navarro \& Campos, 2014; Ferreira Filho \& Vian, 2016).

Como a modernização e o crescimento da agricultura se deram, principalmente, nos empreendimentos agrícolas de maior escala, que possuíam recursos para investirem em tecnologia e na intensificação da produção, surge como questão o fato de o decréscimo da PEA agrícola brasileira estar relacionado à redução do número de empreendimentos agrícolas no Brasil, sobretudo daqueles na posição de conta própria. Apesar da relevância do problema exposto, há poucos estudos acerca dessa temática (Ney \& Hoffmann, 2003, 2008; Hoffmann \& Ney, 2010; Hoffmann, 2011; Telles et al., 2019).

Neste contexto, a hipótese que se depreende dessa questão é que houve uma redução no número de empreendimentos agrícolas, tanto de empregadores quanto de conta própria, e que esse processo se deu de forma desigual entre as diferentes atividades agrícolas e nos diferentes estratos de área, destacando as desigualdades nos processos produtivos decorrentes da modernização da agricultura. Diante de tal constatação e considerando que a caracterização das tendências pode, notadamente, subsidiar tanto o delineamento como a avaliação de ações dirigidas ao meio rural e à segurança alimentar e nutricional no Brasil, o presente estudo teve por objetivo caracterizar a variação do número de empreendimentos agrícolas no país por atividade principal e por estrato de área no período de 2004 a 2015.

Além desta introdução, o artigo encontra-se dividido da seguinte forma: a segunda seção contém a fundamentação teórica que embasa a pesquisa; a terceira seção, a descrição dos materiais e dos procedimentos metodológicos empregados na realização do estudo; a quarta seção, a análise e a discussão dos resultados; e a quinta seção, as conclusões.

\section{FUNDAMENTAÇÃO TEÓRICA}

A intensificação do processo de modernização da agricultura brasileira, fundamentada na produção de commodities em larga escala, resultou em profundos impactos ambientais e 
socioeconômicos em todas as grandes regiões do Brasil, alguns considerados positivos, como o aumento da produtividade de algumas culturas agrícolas (principalmente das commodities agrícolas), outros negativos, como a elevação das taxas de êxodo rural e da concentração fundiária (Mattei, 2015).

Consequentemente, o percentual de brasileiros que vivem no meio rural e se ocupam em atividades agrícolas vem caindo, sistematicamente, desde a década de 19601. Durante a década de 2000, inúmeros estudos foram feitos para analisar as dinâmicas populacionais referentes às pessoas ocupadas no meio rural brasileiro (Del Grossi \& Graziano da Silva, 2006; Ferreira et al., 2006; Laurenti et al., 2015; Balsadi \& Del Grossi, 2016; Telles et al., 2017), realizados, principalmente, a partir da sistematização e análise dos dados da Pesquisa Nacional por Amostra de Domicílios (PNAD), do Instituto Brasileiro de Geografia e Estatística (IBGE).

Del Grossi \& Graziano da Silva (2006) demonstraram que, especialmente a partir dos anos $1990^{2}$, todas as grandes regiões do Brasil apresentaram queda da PEA em atividades agrícolas, fato que os autores atrelaram ao aumento da mecanização agrícola. Ferreira et al. (2006), por sua vez, concluíram, em linhas gerais, que houve no país uma redução da PEA rural ocupada tanto nas ocupações agrícolas como nas não agrícolas. Laurenti et al. (2015), após analisarem dados da PNAD para o período de 2001 a 2009, verificaram que ocorreu retração da PEA rural ocupada em atividade agrícola ${ }^{3}$ e expansão da PEA rural ocupada em atividade não agrícola.

Uma das questões que surge em relação à redução da PEA agrícola no Brasil é em quais atividades agropecuárias ela se dá de forma mais intensa. Porém, poucos estudos buscaram detalhar essa dinâmica, entre os quais se destacam os de Maia \& Sakamoto (2014) e Balsadi \& Del Grossi (2016). Maia \& Sakamoto (2014), por exemplo, observaram que, embora algumas culturas extensivas, como o cultivo de soja e de cana-de-açúcar, detenham grande importância econômica, elas têm participação cada vez menor no total da PEA agrícola ocupada no Brasil. Balsadi \& Del Grossi (2016), por sua vez, verificaram que a PEA agrícola ocupada nas atividades de arroz, café, banana, cana-de-açúcar, cacau, soja, fumo, citricultura e silvicultura foram as que apresentaram as maiores reduções.

Outra questão é em que medida a queda da PEA ocupada em atividades agrícolas está relacionada à redução do número de empreendimentos agrícolas no Brasil. Apesar da relevância do assunto, poucos estudos se dedicaram a analisá-lo, com destaque para os de Hoffmann \& Ney (2010) e Helfand et al. (2014). Por um lado, Hoffmann \& Ney (2010), analisando dados da PNAD para o período de 1992 a 2008, por estrato de área, concluíram que houve uma expressiva diminuição do número de empreendimentos agrícolas no Brasili ${ }^{4}$, principalmente daqueles com área de $\geq 0,1$ a $<10$ hectares (ha). Por outro lado, Helfand et al. (2014), ao analisarem dados dos Censos Agropecuários de 1970 a 2006, constataram que o número de estabelecimentos agrícolas se manteve estável. A divergência entre as conclusões dos estudos pode estar atrelada, em parte, às diferenças conceituais e metodológicas entre a PNAD e os Censos Agropecuários. Na PNAD, as informações se referem aos empreendimentos agrícolas ${ }^{5}$

1 Sobre essa questão, vale destacar o estudo seminal de Santos (2005).

2 Vale ressaltar que, no início dos anos 2000, os empregos agrícolas voltaram a crescer, mas principalmente entre aqueles com domicílio urbano (Del Grossi \& Graziano da Silva, 2006).

${ }^{3}$ Foram consideradas atividades agrícolas para fins comerciais, também denominadas como agricultura mercantil (Laurenti et al., 2015).

${ }^{4}$ Esta tendência é mais nítida a partir de 1999, acentuando-se desde 2004 (Hoffmann \& Ney, 2010).

${ }_{5}^{5} \mathrm{Na}$ PNAD, o empreendimento é definido como a empresa, a instituição, a entidade, a firma, o negócio etc., desenvolvido individualmente ou com ajuda de outras pessoas (empregados, sócios ou trabalhadores não remunerados). Assim, um empreendimento pode ser constituído por um ou mais estabelecimentos. Ademais, é considerada a área do empreendimento para as pessoas que, no trabalho principal da semana de referência, eram conta própria ou empregador em empreendimento de atividade da agricultura, silvicultura ou de criação de bovinos, bubalinos, caprinos, ovinos ou suínos. 
e contemplam apenas às pessoas que têm atividade principal de empregador ou conta própria na agropecuária, sendo esta a fonte de renda predominante da pessoa. Já nos Censos Agropecuários as informações se referem aos estabelecimentos agropecuários ${ }^{6}$, sendo que a agricultura não é, necessariamente, uma importante fonte de renda para o responsável pelo estabelecimento. Por isso, é recenseável todo tipo de exploração agropecuária, comercial ou de subsistência, incluindo chácaras e sítios para lazer - exceto os quintais de residências com pequenos animais e hortas domésticas (Hoffmann \& Ney, 2010).

Diante do exposto, Hoffmann \& Ney (2010) consideram que a base de dados dos Censos Agropecuários não é a mais adequada para análises acerca das tendências e dinâmica do número de estabelecimentos agropecuários. Isso porque, segundo os autores, a manutenção ou o aumento do número de estabelecimentos no país podem estar relacionados à expansão do número de chácaras e sítios para lazer e moradia de quem trabalha na cidade e não depende da agricultura para sobreviver.

Visando evitar possíveis inconsistências atreladas ao problema exposto por Hoffmann \& Ney (2010), o presente estudo optou por utilizar a base de dados da PNAD. Ademais, tal opção também se justifica pelo fato da PNAD captar melhor as áreas e as mudanças referentes aos empreendimentos agrícolas de pessoas físicas, contemplando quase $90 \%$ dos estabelecimentos de conta própria e $96,2 \%$ dos de empregadores ocupados no setor primário (Hoffmann \& Ney, 2010).

Por fim, é necessário salientar que, apesar de extremamente relevante, o estudo de Hoffmann \& Ney (2010) não discorre em quais atividades agrícolas a redução do número de empreendimentos ocorreu em maior intensidade ou de maneira mais significativa. Tal informação é de extrema relevância no contexto da política nacional de segurança alimentar e nutricional, uma vez que pode ter reflexos na oferta de alimentos, como arroz, feijão e mandioca, que são de grande importância para a população brasileira.

Diante de tal constatação, ficam evidentes a importância e a urgência de se conhecer em quais atividades agrícolas e em quais estratos de área a redução do número de empreendimentos vem ocorrendo de maneira mais intensa e significativa.

\section{METODOLOGIA}

Com a finalidade de averiguar as tendências de variação da PEA e do número de empreendimentos agrícolas no Brasil, foi utilizada a base de microdados da PNAD para os anos de 2004 a 20157. Além dos motivos apresentados anteriormente, a utilização da PNAD como base de dados também se justifica por possuir periodicidade anual, o que possibilita a elaboração das taxas anuais de crescimento compostas (ao longo de um período no tempo), permitindo, assim, a verificação da uniformidade da tendência. Além disso, a PNAD capta melhor as áreas de empreendimentos agrícolas de pessoas físicas (Hoffmann \& Ney, 2010).

Foram consideradas informações referentes à PEA ocupada em atividades agrícolas no Brasil, conforme a posição na ocupação. A PEA ocupada se refere ao conjunto de pessoas que tinham trabalho durante pelo menos parte do período da semana de referência, além daquelas que possuíam trabalho remunerado no período especificado, mas que, por algum motivo, não o exerceram (Balsadi \& Del Grossi, 2016). Assim, os dados dizem respeito ao trabalho único ou

\footnotetext{
${ }^{6}$ No Censo Agropecuário, o estabelecimento é classificado como toda unidade de produção dedicada, total ou parcialmente, às atividades agropecuárias, florestais e aquícolas, subordinadas a uma única administração: a do produtor ou a do administrador.

7 O ano de 2010 não é considerado por causa da realização do Censo Demográfico e ausência da PNAD.
} 
principal que a PEA de 10 anos ou mais de idade exercia na semana de referência da PNAD, realizada normalmente na segunda quinzena do mês de setembro de cada ano.

Para cada domicílio amostrado pela PNAD, foi inquirida e registrada informação acerca do empreendimento agropecuário explorado por pessoa, cuja posição na ocupação, na semana de referência da pesquisa, era conta própria ou empregador ${ }^{8}$ e que exerceu atividade principal, ou única, na agricultura, silvicultura ou criação de bovinos, bubalinos, caprinos, ovinos ou suínos.

Ademais, na PNAD, se em um domicílio houver duas ou mais pessoas atuando como conta própria ou empregador em um mesmo empreendimento agrícola, sua área poderá ser informada mais de uma vez. Para evitar esse problema, os dados foram depurados, excluindo-se os casos de "cônjuges" e "filhos" cuja área declarada é igual à da "pessoa de referência" do domicílio.

A fim de se obter um conjunto de informações mais coerente acerca dos empreendimentos agrícolas da PNAD, conforme Hoffmann (2011), foram excluídos das estimativas os casos de conta própria e empregadores que declararam área menor a 0,1 ha e área superior a 10.000 ha.

Com a finalidade de definir a atividade principal dos empreendimentos, a PNAD utiliza as categorias da da Classificação Nacional de Atividades Econômicas (CNAE-Domiciliar), classificando, assim, os empreendimentos de acordo com o código da principal atividade do empreendimento na semana de referência.

O elenco de atividades principais dos empreendimentos considerado neste estudo foi composto por aquelas mais frequentes na PNAD do ano de 2015 para o Brasil: bovinos, milho, soja, hortaliças, fumo, outras lavouras temporárias, café, mandioca, produção mista, arroz, outras lavouras permanentes, ovinos, banana, silvicultura, cacau e outros (outros cereais, algodão, cana-de-açúcar, flores e plantas ornamentais, frutas cítricas, uva, outras plantas e frutas, sementes e mudas, lavouras não especificadas, criação de animais de grande porte não especificados anteriormente, caprinos, suínos, aves, apicultura, sericicultura, outros animais não especificados anteriormente, pecuária não especificada, pesca e aquicultura).

Para o presente estudo foram definidos seis estratos de área, em hectares: $\geq 0,1 \mathrm{a}<1 \mathrm{ha}$; $\geq 1$ a $<5$ ha; $\geq 5$ a $<10$ ha; $\geq 10$ a $<50$ ha; $\geq 50$ a $<100$ ha; e $\geq 100$ a $<10.000$ ha. Se forem definidos em três estratos ( $\geq 0,1 \mathrm{a}<10 ; \geq 10 \mathrm{a}<100$; e $\geq 100 \mathrm{a}<10.000$ ha), haverá o mesmo padrão adotado por Hoffmann \& Ney (2010), permitindo a comparabilidade dos resultados.

A caracterização das tendências de variação do número de empreendimentos por atividade principal foi elaborada com base na taxa média anual de variação composta, calculada com base no antilogaritmo do coeficiente angular da equação do tipo log-linear pelo método de regressão de mínimos quadrados ordinários (MQO), que correlaciona a estimativa do número de empreendimentos existentes ao correspondente ano de observação, conforme Equação 1. Essa taxa de variação foi expressa em percentual, com a aceitabilidade das hipóteses aferidas pela aplicação do teste $t$ de Student, considerando níveis de 1\%, 5\% e 10\% de significância.

$\ln Y_{i}=\alpha+\beta X_{i}+\mu_{i} \quad i=1,2, \ldots, n$

Sendo: a o intercepto; $\beta$ o coeficiente angular da reta; $X$ a variável explanatória referente ao ano correspondente a $i$-ésima observação; $Y$ a variável dependente referente à atividade principal e estrato de área no i-ésimo ano; $\mu$ o erro aleatório; e $i$ o número de anos.

${ }^{8}$ A categoria conta própria se refere aos indivíduos que se ocupam em seus próprios empreendimentos, explorando atividades econômicas sem possuir empregados, de forma individual ou com sócios, com auxílio ou não de trabalhadores não remunerados. A categoria empregador abrange as pessoas que se ocupam em seus próprios empreendimentos, explorando atividades econômicas, individualmente ou com sócios, e com pelo menos um empregado. 
O processamento e a análise dos dados foram realizados utilizando-se do software IBM SPSS $®$ Statistics 23.0 .

\section{RESULTADOS E DISCUSSÃO}

\subsection{PEA ocupada em atividades agrícolas no Brasil}

Na Tabela 1, são apresentados os resultados referentes à evolução da PEA ocupada em atividades agrícolas no Brasil no período de 2004 a 2015. Ao analisar as variações na PEA ocupada em atividades agrícolas no país, é constatado que, entre 2004 e 2015, houve uma redução de mais de 4,5 milhões de pessoas, que representa uma queda da ordem de 2,8\% a.a. Com relação à posição na ocupação, no Brasil, entre 2004 e 2015, houve queda em quase todas as categorias. A PEA agrícola não remunerada foi a que apresentou a maior redução, 10,8\% a.a. Na posição de empregador a queda foi de $7 \%$ a.a., enquanto na categoria conta própria foi de 0,9\% a.a. A mesma análise realizada para os empregados revela uma queda de 2,5\% a.a, sendo que na de empregados sem registro formal a redução foi mais expressiva, atingindo 4\% a.a. A despeito da queda da PEA agrícola nas categorias de empregador e conta própria, que na PNAD são aquelas que detêm a posse da terra, em 2004 elas representavam, em termos relativos, 29\% do total, aumentando para quase 34\% em 2015. Com isso, é verificado que, na soma, empregador e conta própria representam uma parcela relevante da PEA agrícola do Brasil, o que justifica uma análise mais detalhada acerca das tendências relacionadas aos empreendimentos agrícolas, que são relativos a essas categorias.

Tabela 1. População economicamente ativa (PEA) agrícola, de dez anos ou mais de idade, no Brasil, por posição na ocupação no período de 2004 a 2015 (em milhares).

\begin{tabular}{|c|c|c|c|c|c|c|c|c|c|c|c|c|}
\hline $\begin{array}{c}\text { Posição na } \\
\text { ocupação }\end{array}$ & 2004 & 2005 & 2006 & 2007 & 2008 & 2009 & 2011 & 2012 & 2013 & 2014 & 2015 & $i$ \\
\hline Empregador & 559 & 554 & 528 & 411 & 488 & 447 & 352 & 318 & 267 & 269 & 292 & $-7,031^{* * *}$ \\
\hline Conta própria & 4.724 & 4.521 & 4.435 & 4.169 & 4.131 & 4.117 & 4.405 & 3.981 & 3.962 & 4.209 & 4.232 & $-0,923^{* *}$ \\
\hline Empregados & 4.961 & 4.987 & 4.840 & 4.806 & 4.798 & 4.868 & 4.244 & 4.209 & 4.060 & 3.970 & 3.891 & $-2,445 * \star \star$ \\
\hline $\begin{array}{l}\text { Com registro } \\
\text { formal }\end{array}$ & 1.567 & 1.592 & 1.606 & 1.685 & 1.853 & 1.709 & 1.688 & 1.680 & 1.647 & 1.714 & 1.598 & $0,258^{\mathrm{NS}}$ \\
\hline $\begin{array}{l}\text { Sem registro } \\
\text { formal }\end{array}$ & 3.394 & 3.394 & 3.235 & 3.121 & 2.946 & 3.159 & 2.556 & 2.528 & 2.412 & 2.256 & 2.293 & $-3,996 * \star \star$ \\
\hline Não remunerados & 4.350 & 4.084 & 3.625 & 3.510 & 2.876 & 2.772 & 2.083 & 1.737 & 1.457 & 1.592 & 1.308 & $-10,818 * * *$ \\
\hline Autoconsumo & 3.436 & 3.954 & 4.098 & 3.946 & 4.112 & 3.832 & 3.804 & 3.744 & 4.236 & 4.427 & 3.742 & $0,603^{\mathrm{NS}}$ \\
\hline Total & 18.030 & 18.100 & 17.526 & 16.842 & 16.405 & 16.035 & 14.888 & 13.987 & 13.982 & 14.466 & 13.464 & $-2,781 * \star *$ \\
\hline
\end{tabular}

Fonte: elaborada com base nos microdados da Pesquisa Nacional de Amostra por Domicílios (PNAD), do Instituto Brasileiro de Geografia e Estatística (IBGE). Notas: ${ }^{1}$ Taxa média anual de crescimento, estimada pelo coeficiente da regressão log-linear em função do tempo; ***, **, * especificam, respectivamente, o nível de significância de $1 \%, 5 \%$ e $10 \%$, pelo teste $t$ de Student, ${ }^{\text {NS }}$ indica não significativo.

\subsection{Atividades agrícolas em empreendimentos de empregador e conta própria}

A distribuição das atividades principais mais frequentes nos empreendimentos agrícolas, considerando todos aqueles com áreas de $\geq 0,1$ ha a 10.000 ha, é apresentada na Tabela 2. No ano de 2004 as atividades principais dos empreendimentos agrícolas brasileiros, em termos relativos, em ordem decrescente de importância, foram: bovinos (17\%), mandioca (16\%), milho (14\%) e lavouras temporárias (13\%). Juntos, os empreendimentos agrícolas dedicados a essas atividades representaram aproximadamente $60 \%$ do total. 
Tabela 2. Distribuição das atividades agrícolas mais frequentes nos empreendimentos de empregador e conta própria no Brasil no período de 2004 a 2015 (em milhares de empreendimentos).

\begin{tabular}{|c|c|c|c|c|c|c|c|c|c|c|c|c|}
\hline $\begin{array}{l}\text { Atividade } \\
\text { principal }\end{array}$ & 2004 & 2005 & 2006 & 2007 & 2008 & 2009 & 2011 & 2012 & 2013 & 2014 & 2015 & $P$ \\
\hline Bovinos & 770,9 & 864 & 895,4 & 832,1 & 774,2 & 785,7 & 614,7 & 734 & 784,5 & 787,3 & 837,1 & $-0,759^{\mathrm{NS}}$ \\
\hline$(\%)$ & 16,87 & 19,86 & 21,01 & 21,98 & 20,63 & 21,46 & 18,7 & 23,68 & 24,86 & 23,38 & 26,26 & \\
\hline Mandioca & 733,9 & 548,9 & 457,1 & 388,5 & 332,8 & 396,1 & 415,7 & 364 & 369,7 & 472,4 & 369 & $-3,435^{*}$ \\
\hline (\%) & 16,06 & 12,62 & 10,73 & 10,26 & 8,87 & 10,81 & 12,65 & 11,75 & 11,71 & 14,02 & 11,58 & \\
\hline Milho & 646,4 & 605,8 & 616,3 & 593,7 & 517,8 & 522,3 & 583,7 & 462,8 & 396,9 & 425,1 & 353,7 & $-4,721^{* * *}$ \\
\hline$(\%)$ & 14,14 & 13,93 & 14,46 & 15,68 & 13,8 & 14,26 & 17,76 & 14,93 & 12,57 & 12,62 & 11,1 & \\
\hline $\begin{array}{l}\text { Produção } \\
\text { mista }\end{array}$ & 10,4 & 19 & 27 & 39,5 & 197,4 & 304,7 & 372,5 & 307 & 301,7 & 250,5 & 195,1 & $33,990 * * *$ \\
\hline (\%) & 0,23 & 0,44 & 0,63 & 1,04 & 5,26 & 8,32 & 11,33 & 9,91 & 9,56 & 7,43 & 6,12 & \\
\hline Hortaliças & 335,3 & 249,5 & 256,3 & 289 & 200,4 & 214,1 & 201,7 & 171,9 & 204,8 & 219,8 & 212,5 & $-3,526^{* *}$ \\
\hline (\%) & 7,34 & 5,74 & 6,01 & 7,63 & 5,34 & 5,85 & 6,14 & 5,55 & 6,49 & 6,52 & 6,67 & \\
\hline Café & 157,5 & 172,8 & 149,1 & 156,7 & 157,9 & 147,5 & 169,5 & 201,4 & 181,9 & 195,5 & 194,6 & $2,285^{\star * *}$ \\
\hline$(\%)$ & 3,45 & 3,97 & 3,5 & 4,14 & 4,21 & 4,03 & 5,16 & 6,5 & 5,76 & 5,8 & 6,11 & \\
\hline $\begin{array}{l}\text { Lavouras } \\
\text { temporárias }\end{array}$ & 599 & 651,9 & 636,6 & 446,1 & 526,6 & 330,4 & 205 & 154 & 210,1 & 225 & 184,8 & $-12,590 * * *$ \\
\hline (\%) & 13,11 & 14,99 & 14,94 & 11,78 & 14,03 & 9,02 & 6,24 & 4,97 & 6,66 & 6,68 & 5,8 & \\
\hline Soja & 182,5 & 139,5 & 119,3 & 112,5 & 92,2 & 101,8 & 105,8 & 131,1 & 136,8 & 118 & 143,6 & $-0,634^{\mathrm{NS}}$ \\
\hline$(\%)$ & 3,99 & 3,21 & 2,8 & 2,97 & 2,46 & 2,78 & 3,22 & 4,23 & 4,33 & 3,5 & 4,51 & \\
\hline Arroz & 395 & 350,4 & 302 & 192,6 & 204,7 & 232 & 135,2 & 100,6 & 66,6 & 114 & 95,2 & $-13,418 * \star *$ \\
\hline (\%) & 8,64 & 8,06 & 7,09 & 5,09 & 5,45 & 6,33 & 4,11 & 3,25 & 2,11 & 3,38 & 2,99 & \\
\hline Fumo & 180 & 177,7 & 183,6 & 145,7 & 137,6 & 145,4 & 84,9 & 103,2 & 95,3 & 94 & 88 & $-7,262 * * *$ \\
\hline$(\%)$ & 3,94 & 4,09 & 4,31 & 3,85 & 3,67 & 3,97 & 2,58 & 3,33 & 3,02 & 2,79 & 2,76 & \\
\hline $\begin{array}{c}\text { Lavouras } \\
\text { permanentes }\end{array}$ & 146,3 & 122,7 & 158,8 & 100,9 & 123 & 90,8 & 68,2 & 58,6 & 75,2 & 64 & 53,5 & $-8,914$ *** \\
\hline$(\%)$ & 3,2 & 2,82 & 3,73 & 2,67 & 3,28 & 2,48 & 2,08 & 1,89 & 2,38 & 1,9 & 1,68 & \\
\hline Ovinos & 26,8 & 21,6 & 27,1 & 25,7 & 14,3 & 20,3 & 25,8 & 32,8 & 20,1 & 48,8 & 62 & $6,425^{*}$ \\
\hline$(\%)$ & 0,59 & 0,5 & 0,64 & 0,68 & 0,38 & 0,55 & 0,79 & 1,06 & 0,64 & 1,45 & 1,95 & \\
\hline Banana & 78,7 & 99,5 & 81 & 76,3 & 76,9 & 89,8 & 48,9 & 40,5 & 42,3 & 63,8 & 57,8 & $-5,709 * *$ \\
\hline (\%) & 1,72 & 2,29 & 1,9 & 2,02 & 2,05 & 2,45 & 1,49 & 1,31 & 1,34 & 1,89 & 1,81 & \\
\hline Silvicultura & 20,3 & 25 & 30,4 & 29,1 & 29,6 & 34,9 & 36,7 & 44,4 & 42 & 44,2 & 51,5 & $7,397 * \star \star$ \\
\hline$(\%)$ & 0,44 & 0,57 & 0,71 & 0,77 & 0,79 & 0,95 & 1,12 & 1,43 & 1,33 & 1,31 & 1,61 & \\
\hline Cacau & 41,7 & 44,5 & 47,1 & 45,1 & 46,6 & 43,2 & 29,1 & 20,7 & 40,8 & 36,7 & 50,6 & $-2,078^{\mathrm{NS}}$ \\
\hline (\%) & 0,91 & 1,01 & 1,11 & 1,19 & 1,23 & 1,18 & 0,89 & 0,67 & 1,29 & 1,09 & 1,58 & \\
\hline Outros ${ }^{1}$ & 245,3 & 257,2 & 274,6 & 312,3 & 321,3 & 203,6 & 188,9 & 172,1 & 187,7 & 210,4 & 238,3 & $-3,183^{*}$ \\
\hline$(\%)$ & 5,37 & 5,9 & 6,43 & 8,25 & 8,55 & 5,56 & 5,74 & 5,54 & 5,95 & 6,24 & 7,47 & \\
\hline Total & 4570 & 4350 & 4261,7 & 3785,8 & 3753,3 & 3662,6 & 3286,3 & 3099,1 & 3156,4 & 3369,5 & 3187,3 & $-3,364 * * *$ \\
\hline (\%) & 100 & 100 & 100 & 100 & 100 & 100 & 100 & 100 & 100 & 100 & 100 & \\
\hline
\end{tabular}

Fonte: elaborada a partir dos microdados da Pesquisa Nacional por Amostra de Domicílios (PNAD), do Instituto Brasileiro de Geografia e Estatística (IBGE). Notas: ${ }^{1}$ algodão, cana-de-açúcar, flores e plantas ornamentais, frutas cítricas, uva, outras plantas e frutas, sementes e mudas, lavouras não especificadas, criação de animais de grande porte não especificados anteriormente, caprinos, suínos, aves, apicultura, sericicultura, outros animais não especificados anteriormente, pecuária não especificada, pesca e aquicultura. Conforme a composição dos grupamentos de atividades e a relação de códigos de atividades da Classificação Nacional de Atividades Econômicas (CNAE-Domiciliar), sendo que, neste caso, o termo "agricultura" abrange também a pecuária, além de conter a atividade mista de lavoura e pecuária. ${ }^{2}$ Taxa média de crescimento anual expressa em porcentagem. Corresponde à estimativa do coeficiente de uma regressão log-linear contra o tempo. Neste caso, o teste trevela a existência ou não de tendência nos dados; *** indica o nível de significância de 1\%; ** indica o nível de significância de 5\%; * indica o nível de significância de 10\%; NS indica a não significância.

Em 2015, houve um crescimento significativo da participação relativa da bovinocultura, que passou a representar $26 \%$ do total entre as atividades principais realizadas nos empreendimentos agrícolas. A mandioca teve decréscimo na participação e passou a representar $12 \%$ do total das atividades principais realizadas nos empreendimentos agrícolas, o milho, 11\% e as lavouras temporárias, $6 \%$ que, somadas à bovinocultura, corresponderam a 55\% do total. Tais resultados denotam que a composição da atividade principal dos empreendimentos agrícolas no Brasil 
está ligada, sobretudo, aos complexos de carne bovina, leite e grãos, conforme já salientado por Fuentes-Llanillo et al. (2006).

Em síntese, é observado que, entre 2004 e 2015, houve uma queda no número de empreendimentos agropecuários de 1.382 .700 (3,4\% a.a.). Aqueles cujas atividades principais eram de produção mista tiveram aumento de $33,9 \%$ a.a.; os de silvicultura $7,4 \%$ a.a.; os de criação de ovinos $6,4 \%$ a.a.; e os de café $2,3 \%$ a.a. Aqueles dedicados às demais atividades apresentaram queda, sendo as maiores observadas nos de arroz (-13,4\% a.a.), nos de lavouras temporárias $(-12,5 \%$ a.a.) e nos de lavouras permanentes (-8,9\% a.a.).

Balsadi \& Del Grossi (2016) observaram para o Brasil, entre 2004 e 2014, tendência de queda na PEA agrícola ocupada com atividade principal na soja, bem como em culturas como arroz, banana, cana-de açúcar, cacau, fumo e citricultura. Observaram também tendência de aumento na PEA agrícola ocupada com atividade principal na produção mista e na criação de ovinos, resultados semelhantes aos apresentados na Tabela 2. Também para atividades de soja, milho e fumo, os resultados aqui encontrados são condizentes com aqueles apresentados por Maia \& Sakamoto (2014), que, entre os anos de 1992 e 2012, verificaram decréscimo no número de empreendimentos agrícolas na região Sul do Brasil, que se dedicavam ao cultivo das referidas espécies agrícolas.

Em relação à redução do número de empreendimentos agrícolas dedicados às atividades de grãos e cereais, mais especificamente soja e milho, há de se considerar que elas se inserem no contexto de alguns fenômenos importantes, subjacentes às mudanças que ocorreram na ocupação das pessoas em atividades agrícolas. Entre as principais podem ser citadas a intensificação da mecanização produtiva, a introdução de tecnologias, cada vez mais poupadoras de mão de obra, e a adoção de cultivares e sistema de manejo dos solos e fitossanitários que requerem menos operações agrícolas (Ferreira et al., 2006), além da terceirização das atividades agrícolas9.

Um dos efeitos do uso de tecnologias é o aumento da produtividade, como na lavoura da soja, que cresceu 30\% entre 2006 e 2017, e na de milho, que cresceu 56\% (Instituto Brasileiro de Geografia e Estatística, 2019). Todavia, com a introdução das novas técnicas e tecnologias, os custos de produção da soja e do milho passaram a aumentar significativamente ao longo dos anos (Artuzo et al., 2018). Neste contexto, os empreendimentos agrícolas menos capitalizados passaram a enfrentar maiores dificuldades para se manter nessas atividades, ao passo que os mais capitalizados tiveram condições favoráveis para investir e lucrar ainda mais com os cultivos de soja e milho, além de expandirem suas produções a partir da aquisição de novas áreas. Por isso, o aumento da concentração fundiária é um efeito da ampliação da defasagem entre o grande estabelecimento agropecuário e a pequena unidade produtiva, processo favorecido pela intensificação da mecanização da agricultura e necessidade da adoção de novas estratégias de gestão dos empreendimentos agrícolas (Proni \& Garrido, 2005).

Nesse contexto, o aumento da área para o cultivo de commodities como soja e milho, além da cana-de-açúcar, no Brasil, está associado à concentração fundiária (Sauer \& Leite, 2012), à expansão da fronteira agrícola e à incorporação de áreas que estavam sendo utilizadas com outras culturas (consideradas menos rentáveis). Até porque, via de regra, os grandes empreendimentos agrícolas são responsáveis pela produção de commodities, voltadas à exportação, como a soja e a cana-de-açúcar, enquanto os agricultores familiares, que respondem pela maior parte dos empreendimentos agrícolas, são responsáveis pela produção de outros alimentos, como mandioca e leite (Ferreira Filho \& Vian, 2016), que não são commodities e

${ }^{9}$ A terceirização das atividades agrícolas se refere à contratação da prestação de serviços por terceiros, seja de pessoa física ou jurídica, para a execução de determinada atividade no empreendimento rural, que pode incluir máquinas e equipamentos para plantio ou semeadura, controle de daninhas, controles fitossanitários, colheita, entre outros. Também pode se referir apenas à locação de máquinas e equipamentos. Sem ter recursos próprios para aquisição de máquinas e equipamentos ou até mesmo por opção, muitos agricultores passaram a optar pela terceirização, total ou parcial, das atividades agrícolas para ter acesso às operações alinhadas à modernização técnico-produtiva na agropecuária. 
muitas das vezes possuem menor valor agregado ${ }^{10}$. Alguns cultivos agrícolas se inserem em modernas cadeias produtivas com articulação entre o setor privado e as organizações públicas de pesquisa e serviços de extensão rural, como no caso da soja, da cana-de-açúcar, do complexo de carnes e do leite. Enquanto isso, outros ficam à margem dos investimentos em pesquisa e desenvolvimento (P\&D), com restrita integração nas cadeias produtivas e com baixo incentivo ao desenvolvimento tecnológico (Vieira Filho, 2013).

De acordo com os resultados do Censo Agropecuário 2017, os estabelecimentos agropecuários ocupavam uma área de 351,3 milhões de hectares, o que representa um crescimento de 5,3\% em relação a 2006 (Instituto Brasileiro de Geografia e Estatística, 2019). Durante esse período, a área destinada às lavouras temporárias cresceu aproximadamente 14\%, passando de 48,9 milhões para 55,8 milhões de hectares, embora sua participação em relação à área ocupada pelos estabelecimentos agropecuários tenha passado de 14,7\% para 15,9\% da área total. É possível destacar, neste cenário, o crescimento da cultura da soja no país. A área colhida do grão cresceu 71,8\% entre 2006 e 2017, passando de 17,9 milhões para 30,7 milhões de hectares colhidos. Sua participação relativa na agropecuária brasileira apresentou um grande salto: em 2006, a soja representava $36,6 \%$ da área total das lavouras temporárias do país, e, em 2017, esse percentual passou para 55,1\%. A cultura da cana-de-açúcar também se expandiu no período, indo, entre 2006 e 2017, de 5,7 milhões para 9,1 milhões de hectares colhidos. As áreas de pastagens destinadas à criação de bovinos, sejam elas naturais ou plantadas, ocupam uma porção expressiva da área agropecuária brasileira. Em 2006, a área de pastagem era de 160 milhões de hectares, ou seja, 48\% do total da área agropecuária do país; já em 2017, essa área passou para 159,5 milhões de hectares, ocupando, em termos relativos, 45,4\% da área total da agropecuária.

Além disso, os dados censitários revelam a desigualdade na distribuição da terra no Brasil. Em 2006, os estabelecimentos agropecuários com área igual ou maior que 100 hectares, que representavam 9,6\% do total, concentravam 78,6\% da área agropecuária do país; já em 2017, passaram a representar $9,3 \%$ do total, concentrando $79,6 \%$ da área.

Tais entendimentos explicitam que a intensificação da concentração fundiária no Brasil está associada, entre outros fatores, à expansão de modelos e lógicas produtivas de commodities, que, consequentemente, influenciam a dinâmica nacional de produção e oferta de alimentos "não comoditizados", como o feijão e a mandioca.

Para melhor observar e discutir o problema exposto, é necessário analisar quais atividades agrícolas apresentaram redução ou aumento no número de estabelecimentos dedicados a elas. Para tanto, e visando favorecer a melhor exposição e discussão do assunto, os resultados foram divididos em dois blocos: (i) distribuição das atividades agrícolas nos empreendimentos de empregador (Tabela 3), as quais representam, em média, 9,8\% do total de empreendimentos agropecuários; (ii) e distribuição das atividades agrícolas nos empreendimentos de conta própria (Tabela 4), as quais representam, em média, 90,2\% do total de empreendimentos.

\subsubsection{Distribuição das atividades agrícolas nos empreendimentos de empregador}

A distribuição das atividades principais mais frequentes nos empreendimentos agrícolas da categoria empregador, considerando todos aqueles com áreas de $\geq 0,1$ ha a 10.000 ha, é apresentada na Tabela 3. No ano de 2004, as atividades principais de empreendimentos agrícolas brasileiros de empregador, em termos relativos, em ordem decrescente de importância,

${ }^{10} \mathrm{~A}$ agricultura familiar, em pequenas unidades produtivas, é responsável por grande parte da produção nacional de alimentos (cerca de $87 \%$ da produção de mandioca e de $70 \%$ da produção de feijão), garantindo a segurança alimentar do país, e ainda emprega mais de 74\% das pessoas ocupadas na agricultura (Rocha et al., 2012). 
foram bovinos (33,3\%), outros (7,9\%), soja (7,8\%) e lavouras temporárias $(7,7 \%)$, que, juntos, representavam aproximadamente $56 \%$ do total. Em 2015, houve crescimento significativo da participação relativa da bovinocultura, que passou a representar $44,9 \%$ do total das atividades principais realizadas nesses empreendimentos agrícolas, sendo que outros $(8,4 \%)$, soja $(8,2 \%)$ e lavouras temporárias registraram decréscimo na participação e passaram a representar, em conjunto, apenas 3\% do total. Resultado semelhante foi encontrado na pesquisa de Sakamoto \& Maia (2012), em que as atividades agrícolas no Brasil, no período de 1992 a 2012, concentravamse no cultivo de cereais e outros produtos de lavoura, criação de bovinos e outros animais.

Tabela 3. Distribuição das atividades agrícolas mais frequente nos empreendimentos de empregador no Brasil no período de 2004 a 2015 (em milhares de empreendimentos).

\begin{tabular}{|c|c|c|c|c|c|c|c|c|c|c|c|c|}
\hline $\begin{array}{l}\text { Atividade } \\
\text { principal }\end{array}$ & 2004 & 2005 & 2006 & 2007 & 2008 & 2009 & 2011 & 2012 & 2013 & 2014 & 2015 & $P^{2}$ \\
\hline Bovinos & 174 & 205,4 & 172,4 & 132,6 & 143,6 & 149,4 & 96,6 & 113,9 & 104,3 & 114,2 & 114,5 & $-5,269^{* * *}$ \\
\hline (\%) & 33,33 & 40,25 & 35,32 & 34,91 & 32,97 & 37,29 & 33,57 & 41,49 & 45,45 & 47,52 & 44,92 & \\
\hline Mandioca & 37,4 & 15,7 & 14,8 & 10,3 & 18,5 & 12,7 & 12,4 & 7,1 & 4,1 & 8,6 & 5,5 & $-12,664 * * \star$ \\
\hline$(\%)$ & 7,16 & 3,08 & 3,03 & 2,71 & 4,25 & 3,17 & 4,31 & 2,59 & 1,79 & 3,58 & 2,16 & \\
\hline Milho & 27,5 & 32,1 & 37,6 & 25,3 & 26,4 & 22,6 & 21,1 & 14,2 & 8,1 & 11 & 10 & $-11,602 * * *$ \\
\hline (\%) & 5,27 & 6,29 & 7,7 & 6,66 & 6,06 & 5,64 & 7,33 & 5,17 & 3,53 & 4,58 & 3,92 & \\
\hline $\begin{array}{l}\text { Produção } \\
\text { mista }\end{array}$ & 2,7 & 3,3 & 7,1 & 11,5 & 38,4 & 42,5 & 28 & 26,4 & 23,3 & 13 & 10,9 & $7,204^{*}$ \\
\hline (\%) & 0,52 & 0,65 & 1,45 & 3,03 & 8,82 & 10,61 & 9,73 & 9,62 & 10,15 & 5,41 & 4,28 & \\
\hline Hortaliças & 23,1 & 24,3 & 24,4 & 21,3 & 21,1 & 18,6 & 16,1 & 13,5 & 13,7 & 9,4 & 16,4 & $-6,605 * * *$ \\
\hline (\%) & 4,42 & 4,76 & 5 & 5,61 & 4,84 & 4,64 & 5,59 & 4,92 & 5,97 & 3,91 & 6,43 & \\
\hline Café & 28,7 & 21,9 & 22,8 & 23,5 & 23,7 & 14,1 & 22,6 & 23,2 & 13,8 & 12,5 & 19,4 & $-4,361^{* *}$ \\
\hline (\%) & 5,5 & 4,29 & 4,67 & 6,19 & 5,44 & 3,52 & 7,85 & 8,45 & 6,01 & 5,2 & 7,61 & \\
\hline $\begin{array}{l}\text { Lavouras } \\
\text { temporárias }\end{array}$ & 40 & 26,4 & 31,2 & 15,6 & 28,5 & 13,2 & 12 & 7,9 & 5,9 & 8,5 & 7,6 & $-14,883^{* \star \star}$ \\
\hline (\%) & 7,66 & 5,17 & 6,39 & 4,11 & 6,54 & 3,3 & 4,17 & 2,88 & 2,57 & 3,54 & 2,98 & \\
\hline Soja & 40,5 & 31,3 & 25,4 & 24,4 & 16,5 & 23,2 & 24,2 & 22,2 & 17,1 & 17,9 & 20,9 & $-4,918 * *$ \\
\hline (\%) & 7,76 & 6,13 & 5,2 & 6,42 & 3,79 & 5,79 & 8,41 & 8,09 & 7,45 & 7,45 & 8,2 & \\
\hline Arroz & 28,9 & 29 & 25,2 & 11,4 & 17,1 & 11,8 & 10,8 & 5 & 2,1 & 0,9 & 4,4 & $-23,132^{* * *}$ \\
\hline (\%) & 5,54 & 5,68 & 5,16 & 3 & 3,93 & 2,95 & 3,75 & 1,82 & 0,92 & 0,37 & 1,73 & \\
\hline Fumo & 19,6 & 30,2 & 30,2 & 17,2 & 17,2 & 19,7 & 2,4 & 2,4 & 2,1 & 0,1 & 3,6 & 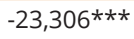 \\
\hline (\%) & 3,75 & 5,92 & 6,18 & 4,53 & 3,95 & 4,92 & 0,83 & 0,87 & 0,92 & 0,04 & 1,41 & \\
\hline $\begin{array}{c}\text { Lavouras } \\
\text { permanentes }\end{array}$ & 33,6 & 23,5 & 29,5 & 16,9 & 28,4 & 18,9 & 7,2 & 8,5 & 10,8 & 7,6 & 5,8 & $-14,399 * * *$ \\
\hline$(\%)$ & 6,44 & 4,61 & 6,04 & 4,45 & 6,52 & 4,72 & 2,5 & 3,1 & 4,71 & 3,16 & 2,28 & \\
\hline Ovinos & 1,4 & 2,6 & 3,3 & 4,7 & 3 & 2,2 & 1,8 & 2,1 & 0,6 & 1,6 & 3 & $-4,677^{\mathrm{NS}}$ \\
\hline (\%) & 0,27 & 0,51 & 0,68 & 1,24 & 0,69 & 0,55 & 0,63 & 0,77 & 0,26 & 0,67 & 1,18 & \\
\hline Banana & 15,5 & 10,7 & 6,7 & 12,3 & 5,9 & 13,7 & 2,5 & 3,9 & 2,1 & 5,9 & 3,3 & $-12,987 * \star \star *$ \\
\hline (\%) & 2,97 & 2,1 & 1,37 & 3,24 & 1,35 & 3,42 & 0,87 & 1,42 & 0,92 & 2,46 & 1,29 & \\
\hline Silvicultura & 0,6 & 3 & 5,1 & 3,6 & 4,5 & 3,3 & 2,8 & 5,7 & 1,6 & 5,4 & 7 & $9,355^{\mathrm{NS}}$ \\
\hline (\%) & 0,11 & 0,59 & 1,04 & 0,95 & 1,03 & 0,82 & 0,97 & 2,08 & 0,7 & 2,25 & 2,75 & \\
\hline Cacau & 7,5 & 9,7 & 4,9 & 4,8 & 5,9 & 3,7 & 1,8 & 0,7 & 2,6 & 3,4 & 1,3 & $-14,998 * * *$ \\
\hline (\%) & 1,44 & 1,9 & 1 & 1,26 & 1,35 & 0,92 & 0,63 & 0,26 & 1,12 & 1,41 & 0,51 & \\
\hline Outros ${ }^{1}$ & 41,1 & 41,2 & 47,7 & 44,4 & 36,9 & 31 & 25,5 & 17,8 & 17,3 & 20,3 & 21,3 & $-8,811 * * *$ \\
\hline (\%) & 7,86 & 8,07 & 9,77 & 11,69 & 8,47 & 7,74 & 8,86 & 6,47 & 7,53 & 8,45 & 8,35 & \\
\hline Total & 522,1 & 510,3 & 488,3 & 379,8 & 435,6 & 400,6 & 287,8 & 274,5 & 229,5 & 240,3 & 254,9 & $-7,725 * \star \star$ \\
\hline (\%) & 100 & 100 & 100 & 100 & 100 & 100 & 100 & 100 & 100 & 100 & 100 & \\
\hline
\end{tabular}

Fonte: elaborada a partir dos microdados da Pesquisa Nacional por Amostra de Domicílios (PNAD), do Instituto Brasileiro de Geografia e Estatística (IBGE). Notas: ${ }^{1}$ algodão, cana-de-açúcar, flores e plantas ornamentais, frutas cítricas, uva, outras plantas e frutas, sementes e mudas, lavouras não especificadas, criação de animais de grande porte não especificados anteriormente, caprinos, suínos, aves, apicultura, sericicultura, outros animais não especificados anteriormente, pecuária não especificada, pesca e aquicultura. Conforme a composição dos grupamentos de atividades e a relação de códigos de atividades da Classificação Nacional de Atividades Econốmicas (CNAE-Domiciliar), sendo que, neste caso, o termo "agricultura" abrange também a pecuária, além de conter a atividade mista de lavoura e pecuária. ${ }^{2}$ Taxa média de crescimento anual expressa em porcentagem. Corresponde à estimativa do coeficiente de uma regressão log-linear contra o tempo. Neste caso, o teste trevela a existência ou não de tendência nos dados; *** indica o nível de significância de 1\%; ** indica o nível de significância de 5\%; * indica o nível de significância de 10\%; e NS indica a não significância. 
Entre 2004 e 2015, as atividades que registraram acréscimo no número de estabelecimentos agropecuários foram: produção mista (7,2\% a.a.) e silvicultura ( $9,3 \%$ a.a.). Todas as demais atividades apresentaram decréscimo, com destaque para o fumo (-23,3\% a.a.), o arroz (-23,1\% a.a.), o cacau (-15\% a.a.), as lavouras temporárias $(-14,9 \%$ a.a.) e as lavouras permanentes $(-14,4 \%$ a.a.).

Ademais, merecem ser salientados os decréscimos no número de empreendimentos dedicados a produção de mandioca $(-12,7 \%$ a.a.) e banana (-13\% a.a.), uma vez que estes produtos são considerados alimentos básicos na dieta dos brasileiros, sendo oportuno destacar que a banana e a laranja são as frutas mais consumidas no Brasil (Instituto Brasileiro de Geografia e Estatística, 2020).

Quanto ao número de empreendimentos agrícolas de empregador, o total foi reduzido a menos da metade, entre 2004 e 2015, caindo de 522.100 para 254.900, o que representa uma redução de $7,7 \%$ a.a. Tal constatação merece ser ressaltada, especialmente porque pode vir a resultar em menor oferta de postos de ocupação em atividades agrícolas, o que, por sua vez, pode favorecer ainda mais o processo de êxodo rural no Brasil.

\subsubsection{Distribuição das atividades agrícolas nos empreendimentos de conta própria}

A distribuição das atividades principais mais frequentes nos empreendimentos agrícolas da categoria conta própria, considerando todos aqueles com áreas de $\geq 0,1$ ha a 10.000 ha, é apresentada na Tabela 4.

No ano de 2004, as atividades principais dos empreendimentos agrícolas brasileiros de conta própria, em ordem decrescente de participação relativa, foram mandioca (17,2\%), milho (15,3\%), bovinos (14,8\%) e lavouras temporárias (13,8\%), que, juntos, representaram aproximadamente $61 \%$ do total. Em 2015, houve crescimento significativo da participação relativa da bovinocultura, que passou a representar $24,6 \%$ do total das atividades principais realizadas nos empreendimentos agrícolas, porém aqueles dedicados à mandioca, ao milho e às lavouras temporárias obtiveram decréscimo na participação, representando $12,4 \%, 11,7 \%$ e $6 \%$, respectivamente.

Os empreendimentos agrícolas de conta própria, cujas atividades principais são baseadas na produção mista, em ovinos e na silvicultura, obtiveram aumentos de $37,4 \%$ a.a., 7,5\% a.a. e 7,4\% a.a., respectivamente, enquanto aqueles dedicados às demais atividades apresentaram queda, sendo os maiores decréscimos observados na atividade do arroz ( $-13 \%$ a.a.) e nas lavouras temporárias (-12,5\% a.a.).

A drástica redução no número de empreendimentos agrícolas de conta própria que se dedicam ao cultivo de arroz, mandioca (-3,7\% a.a.) e outras lavouras temporárias (como o feijão) merece ser melhor analisada, sobretudo por estar relacionada à oferta de alimentos básicos da dieta dos brasileiros, o que pode impactar na segurança alimentar e nutricional da população e, assim, favorecer o processo de redução da diversidade de cultivares dessas culturas, uma vez que, costumeiramente, agricultores familiares são responsáveis por conservar sementes "antigas", tradicionais ou crioulas. De acordo com Bevilaqua et al. (2014), os agricultores familiares são "guardiões de sementes crioulas", já que as multiplicam e as conservam por inúmeras gerações.

O fenômeno de redução no número de empreendimentos agrícolas de conta própria dedicados ao cultivo de lavouras temporárias, como arroz, milho e feijão, pode ser abordado como um dos efeitos do processo de mercantilização da agricultura e da especialização produtiva vivenciado por agricultores familiares brasileiros (Grisa \& Schneider, 2008; Anjos et al., 2009). Os agricultores, via de regra, na busca por maiores rendimentos, tendem a optar por direcionar boa parte de seus recursos produtivos à realização de atividades agrícolas que demandem pouca mão de obra e ofereçam menor risco de perdas por estresses climáticos e "comercialização assegurada" por contratos com agroindústrias, tais como abatedouros, indústrias de processamento de frutas, papel e celulose. 
Tabela 4. Distribuição das atividades agrícolas mais frequentes nos empreendimentos de conta própria no meio rural do Brasil no período de 2004 a 2015 (em milhares de empreendimentos).

\begin{tabular}{|c|c|c|c|c|c|c|c|c|c|c|c|c|}
\hline $\begin{array}{l}\text { Atividade } \\
\text { principal }\end{array}$ & 2004 & 2005 & 2006 & 2007 & 2008 & 2009 & 2011 & 2012 & 2013 & 2014 & 2015 & $P$ \\
\hline Bovinos & 596,9 & 658,7 & 723 & 699,4 & 630,7 & 636,2 & 518 & 620,2 & 680,3 & 673,1 & 722,5 & $0,244^{\mathrm{NS}}$ \\
\hline$(\%)$ & 14,75 & 17,15 & 19,16 & 20,53 & 19,01 & 19,50 & 17,28 & 21,96 & 23,24 & 21,51 & 24,64 & \\
\hline Mandioca & 696,5 & 533,3 & 442,4 & 378,1 & 314,3 & 383,3 & 403,2 & 356,9 & 365,6 & 463,8 & 363,5 & $-3,172^{*}$ \\
\hline (\%) & 17,21 & 13,89 & 11,72 & 11,10 & 9,47 & 11,75 & 13,45 & 12,64 & 12,49 & 14,82 & 12,40 & \\
\hline Milho & 618,9 & 573,7 & 578,7 & 568,4 & 491,4 & 499,7 & 562,7 & 448,6 & 388,9 & 414 & 343,7 & $-4,446^{* * *}$ \\
\hline$(\%)$ & 15,29 & 14,94 & 15,34 & 16,69 & 14,81 & 15,32 & 18,77 & 15,88 & 13,29 & 13,23 & 11,72 & \\
\hline $\begin{array}{l}\text { Produção } \\
\text { mista }\end{array}$ & 7,7 & 15,6 & 19,8 & 28 & 159 & 262,2 & 344,5 & 280,6 & 278,4 & 237,5 & 184,2 & $37,388 * * *$ \\
\hline$(\%)$ & 0,19 & 0,41 & 0,52 & 0,82 & 4,79 & 8,04 & 11,49 & 9,93 & 9,51 & 7,59 & 6,28 & \\
\hline Hortaliças & 312,2 & 225,2 & 231,9 & 267,7 & 179,3 & 195,5 & 185,6 & 158,4 & 191 & 210,4 & 196,1 & $-3,285^{* *}$ \\
\hline$(\%)$ & 7,71 & 5,87 & 6,15 & 7,86 & 5,40 & 5,99 & 6,19 & 5,61 & 6,53 & 6,72 & 6,69 & \\
\hline Café & 128,8 & 150,8 & 126,3 & 133,2 & 134,2 & 133,4 & 146,8 & 178,3 & 168,2 & 183 & 175,2 & $3,192 * * *$ \\
\hline$(\%)$ & 3,18 & 3,93 & 3,35 & 3,91 & 4,05 & 4,09 & 4,90 & 6,31 & 5,75 & 5,85 & 5,97 & \\
\hline $\begin{array}{l}\text { Lavouras } \\
\text { temporárias }\end{array}$ & 559,1 & 625,5 & 605,3 & 430,5 & 498,1 & 317,2 & 193 & 146,1 & 204,3 & 216,5 & 177,2 & $-12,477 * \star \star *$ \\
\hline (\%) & 13,81 & 16,29 & 16,04 & 12,64 & 15,01 & 9,72 & 6,44 & 5,17 & 6,98 & 6,92 & 6,04 & \\
\hline Soja & 142 & 108,2 & 93,8 & 88,1 & 75,6 & 78,7 & 81,6 & 108,9 & 119,7 & 100 & 122,7 & $0,320^{\mathrm{NS}}$ \\
\hline$(\%)$ & 3,51 & 2,82 & 2,49 & 2,59 & 2,28 & 2,41 & 2,72 & 3,86 & 4,09 & 3,20 & 4,18 & \\
\hline Arroz & 366,1 & 321,4 & 276,8 & 181,3 & 187,6 & 220,2 & 124,4 & 95,6 & 64,5 & 113,1 & 90,8 & $-12,975 * \star *$ \\
\hline$(\%)$ & 9,04 & 8,37 & 7,34 & 5,32 & 5,65 & 6,75 & 4,15 & 3,38 & 2,20 & 3,61 & 3,10 & \\
\hline Fumo & 160,5 & 147,6 & 153,4 & 128,5 & 120,3 & 125,7 & 82,6 & 100,9 & 93,2 & 94 & 84,4 & $-5,799 * * *$ \\
\hline (\%) & 3,97 & 3,84 & 4,07 & 3,77 & 3,63 & 3,85 & 2,75 & 3,57 & 3,18 & 3,00 & 2,88 & \\
\hline $\begin{array}{c}\text { Lavouras } \\
\text { permanentes }\end{array}$ & 112,7 & 99,2 & 129,2 & 83,9 & 94,6 & 71,9 & 60,9 & 50,1 & 64,4 & 56,4 & 47,7 & $-7,829 * \star \star$ \\
\hline (\%) & 2,78 & 2,58 & 3,42 & 2,46 & 2,85 & 2,20 & 2,03 & 1,77 & 2,20 & 1,80 & 1,63 & \\
\hline Ovinos & 25,5 & 19 & 23,8 & 21 & 11,3 & 18,1 & 24,1 & 30,7 & 19,6 & 47,2 & 59 & $7,458^{*}$ \\
\hline$(\%)$ & 0,63 & 0,49 & 0,63 & 0,62 & 0,34 & 0,55 & 0,80 & 1,09 & 0,67 & 1,51 & 2,01 & \\
\hline Banana & 63,1 & 88,9 & 74,3 & 64,1 & 71 & 76 & 46,4 & 36,6 & 40,2 & 58 & 54,6 & $-4,813^{\star \star}$ \\
\hline (\%) & 1,56 & 2,32 & 1,97 & 1,88 & 2,14 & 2,33 & 1,55 & 1,30 & 1,37 & 1,85 & 1,86 & \\
\hline Silvicultura & 19,7 & 21,9 & 25,3 & 25,5 & 25,1 & 31,7 & 33,9 & 38,7 & 40,4 & 38,7 & 44,5 & $7,365^{* * *}$ \\
\hline$(\%)$ & 0,49 & 0,57 & 0,67 & 0,75 & 0,76 & 0,97 & 1,13 & 1,37 & 1,38 & 1,24 & 1,52 & \\
\hline Cacau & 34,1 & 34,8 & 42,2 & 40,3 & 40,7 & 39,5 & 27,3 & 20 & 38,2 & 33,3 & 49,4 & $-0,638^{\mathrm{NS}}$ \\
\hline$(\%)$ & 0,84 & 0,91 & 1,12 & 1,18 & 1,23 & 1,21 & 0,91 & 0,71 & 1,31 & 1,06 & 1,68 & \\
\hline Outros $^{1}$ & 204,1 & 215,9 & 227,2 & 268 & 284,4 & 172,7 & 163,4 & 154 & 170 & 190,2 & 216,9 & $-2,341^{\mathrm{NS}}$ \\
\hline$(\%)$ & 5,04 & 5,62 & 6,02 & 7,87 & 8,57 & 5,29 & 5,45 & 5,45 & 5,81 & 6,08 & 7,40 & \\
\hline Total & 4047,9 & 3839,7 & 3773,4 & 3406 & 3317,6 & 3262 & 2998,4 & 2824,6 & 2926,9 & 3129,2 & 2932,4 & $-2,899 * \star *$ \\
\hline (\%) & 100 & 100 & 100 & 100 & 100 & 100 & 100 & 100 & 100 & 100 & 100 & \\
\hline
\end{tabular}

Fonte: elaborada a partir dos microdados da Pesquisa Nacional por Amostra de Domicílios (PNAD), do Instituto Brasileiro de Geografia e Estatística (IBGE). Notas: ${ }^{1}$ algodão, cana-de-açúcar, flores e plantas ornamentais, frutas cítricas, uva, outras plantas e frutas, sementes e mudas, lavouras não especificadas, criação de animais de grande porte não especificados anteriormente, caprinos, suínos, aves, apicultura, sericicultura, outros animais não especificados anteriormente, pecuária não especificada, pesca e aquicultura. Conforme a composição dos grupamentos de atividades e a relação de códigos de atividades da Classificação Nacional de Atividades Econốmicas (CNAE-Domiciliar), sendo que, neste caso, o termo "agricultura" abrange também a pecuária, além de conter a atividade mista de lavoura e pecuária. ${ }^{2}$ Taxa média de crescimento anual expressa em porcentagem. Corresponde à estimativa do coeficiente de uma regressão log-linear contra o tempo. Neste caso, o teste trevela a existência ou não de tendência nos dados; *** indica o nível de significância de 1\%; ** indica o nível de significância de 5\%; * indica o nível de significância de 10\%; e NS indica a não significância.

Considerando que os cultivos de arroz, milho e feijão, do plantio à colheita, apresentam alta demanda de mão de obra e suscetibilidade a perdas por problemas climáticos, resultando em alimentos que podem ser adquiridos com relativa facilidade em mercados locais, agricultores familiares sentem-se desestimulados ou desencorajados a dedicar seus esforços e investir seus recursos produtivos em tais culturas agrícolas. 
Neste contexto, agricultores familiares tendem a direcionar o uso da mão de obra e de áreas de produção à realização de criações ou "cultivos comerciais" que possuam menor risco de perdas por estresses climáticos e maior potencial para gerar renda do que lavouras temporárias, como é o caso da ovinocultura e silvicultura, que, conforme observado anteriormente, registraram aumento no número de empreendimentos agropecuários.

Sobre a silvicultura, é oportuno destacar que tal atividade teve participação aumentada, tanto nos empreendimentos agrícolas de empregador como nos de conta própria. A justificativa para isso se deve ao fato de a silvicultura representar uma boa alternativa de renda, especialmente para as pequenas e médias unidades produtivas que possuem áreas impróprias para o desenvolvimento de lavouras temporárias, ou seja, a silvicultura tem características ambientais que a tornam preferível a outras atividades rurais, por poder ser explorada em terrenos declivosos (Fischer et al., 2015).

No que concerne ao número de empreendimentos agrícolas de conta própria, os dados da PNAD indicam redução de aproximadamente 1.115.500 estabelecimentos entre 2004 e 2015, resultando em decréscimo de 2,9\% a.a. Tal constatação é relevante, pois se relaciona à redução da oferta e da ocupação de empregos agrícolas no meio rural brasileiro, já que a grande maioria destes se dá na agricultura familiar ${ }^{11}$.

\subsection{Evolução do número de empreendimentos agrícolas no Brasil entre 2004 e 2015}

Na Tabela 5 é apresentada a evolução do número de empreendimentos agrícolas no Brasil, com estratos de áreas de $\geq 0,1 \mathrm{a}<1 \mathrm{ha}, \geq 1 \mathrm{a}<5 \mathrm{ha}, \geq 5 \mathrm{a}<10 \mathrm{ha}, \geq 10 \mathrm{a}<50 \mathrm{ha}, \geq 50 \mathrm{a}<100$ ha e $\geq 100 \mathrm{a}$ $<10.000$ ha, de acordo com os dados das PNAD, de 2004 a 2015, para empregador e conta própria.

Em termos relativos, em 2004 os empreendimentos agrícolas estavam distribuídos em ordem decrescente de importância nos estratos $\geq 1$ a $<5$ ha $(32,7 \%), \geq 10$ a $<50$ ha $(29,3 \%)$, $\geq 5$ a $<10$ ha $(12,2 \%), \geq 0,1$ a $<1$ ha $(10,2 \%), \geq 100$ a $<10.000$ ha $(8,7 \%)$ e $\geq 50$ a $<100$ ha $(6,9 \%)$. Em 2015, houve pouca mudança na distribuição dos empreendimentos agrícolas, em relação ao ano de 2014 ; assim, em ordem decrescente de importância, a composição dos estratos ficaram da seguinte maneira: $\geq 1 \mathrm{a}<5$ ha $(31,6 \%), \geq 10 \mathrm{a}<50$ ha $(28,9 \%), \geq 0,1 \mathrm{a}<1$ ha $(13 \%)$, $\geq 5 \mathrm{a}<10$ ha $(11,8 \%), \geq 100 \mathrm{a}<10.000$ ha $(8,1 \%)$ e $\geq 50 \mathrm{a}<100$ ha $(6,6 \%)$.

Em geral, é observada uma tendência de queda no número de empreendimentos agrícolas, da ordem de 3,4\% a.a. Além disso, é constatado que, no estrato de área $\geq 50$ a < 100 ha, houve a maior taxa de redução no número de empreendimentos agrícolas (-4,5 a.a.). Já no estrato de área de $\geq 5$ a $<10$ ha, houve a menor taxa de redução no número de empreendimentos agrícolas (-3,3\% a.a.).

Ao comparar as taxas de crescimento anuais, é possível perceber, de modo geral, que a redução no número de empreendimentos agrícolas de empregador foi mais acentuada do que no de conta própria. Essa constatação é mais clara quando se observam as taxas de crescimento para as duas posições de ocupação no estrato $\geq 1$ a < 5 ha, em que para empregador a taxa é de -9,3\% a.a. e para conta própria é de $-4 \%$ a.a. Essa tendência também é observada quando se trata da população ocupada agrícola, sendo apontada nos estudos de Sakamoto \& Maia (2012), Maia \& Sakamoto (2014), Laurenti et al. (2015), Balsadi \& Del Grossi (2016) e Telles et al. (2017), uma vez que o número de empreendimentos agrícolas tem relação direta com o número de pessoas que vivem no meio rural. Vale destacar ainda, segundo Ney \& Hoffmann (2003), que as informações sobre a área na PNAD se referem às pessoas que têm a produção agropecuária como importante fonte de renda, tendo em vista que sua ocupação principal deve ser de empregador ou conta própria na atividade. Nesse sentido, a redução no número de empreendimentos agrícolas reflete uma variação daqueles cuja renda tende a ter uma forte relação com a área cultivada.

${ }^{11}$ Esta abrange as categorias conta própria e não remunerados, além de boa parte dos trabalhadores na produção para o autoconsumo (Mattei, 2015). 
Tabela 5. Distribuição de empreendimentos agrícolas no Brasil por estrato de área no período de 2004 a 2015 (em milhares de empreendimentos).

\begin{tabular}{|c|c|c|c|c|c|c|c|c|c|c|c|c|}
\hline Estratos d & 2004 & 2005 & 2006 & 2007 & 2008 & 2009 & 2011 & 2012 & 2013 & 2014 & 2015 & $P$ \\
\hline \multicolumn{13}{|c|}{ Total } \\
\hline$\geq 0,1 \mathrm{a}<$ & 465,5 & 433,9 & 416,5 & 383,9 & 366,3 & 395,5 & 500,9 & 419,2 & 356,1 & 525,2 & 413,1 & $0,26^{N S}$ \\
\hline$(\%)$ & 10,19 & 9,97 & 9,77 & 10,14 & 9,76 & 10,80 & 15,24 & 13,53 & 11,28 & 15,59 & 12,96 & \\
\hline$\geq 1 \mathrm{a}<5$ ha & 1494,2 & 1483,6 & 1446,7 & 1165,8 & 1247,3 & 1165,1 & 981,5 & 899,7 & 1002,2 & 1034,6 & 1007,6 & $-4,17 * \star \star *$ \\
\hline (\%) & 32,70 & 34,10 & 33,95 & 30,79 & 33,23 & 31,81 & 29,87 & 29,03 & 31,75 & 30,70 & 31,61 & \\
\hline$\geq 5 \mathrm{a}<10$ ha & 558,2 & 502,2 & 512,2 & 480,2 & 490,2 & 463,3 & 384,6 & 393,9 & 409,5 & 400,6 & 376,9 & $-3,3 * * *$ \\
\hline (\%) & 12,21 & 11,54 & 12,02 & 12,68 & 13,06 & 12,65 & 11,70 & 12,71 & 12,97 & 11,89 & 11,82 & \\
\hline$\geq 10 \mathrm{a}<50$ ha & 1339,1 & 1231,1 & 1177,7 & 1183,4 & 1065,8 & 1066 & 936,7 & 905,7 & 950,9 & 912,8 & 921,3 & $-3,45 * \star *$ \\
\hline (\%) & 29,30 & 28,30 & 27,63 & 31,26 & 28,40 & 29,11 & 28,50 & 29,22 & 30,13 & 27,09 & 28,91 & \\
\hline$\geq 50 \mathrm{a}<100 \mathrm{ha}$ & 317 & 305 & 323,3 & 275,2 & 242,9 & 287,7 & 216,9 & 209 & 195,8 & 213,9 & 209,4 & $-4,49 * \star *$ \\
\hline$(\%)$ & 6,94 & 7,01 & 7,59 & 7,27 & 6,47 & 7,86 & 6,60 & 6,74 & 6,20 & 6,35 & 6,57 & \\
\hline$\geq 100 \mathrm{a}<10.000$ ha & 396,1 & 394,3 & 385,3 & 297,3 & 340,8 & 285 & 265,6 & 271,6 & 242 & 282,4 & 259 & $-4,13^{* * *}$ \\
\hline$(\%)$ & 8,67 & 9,06 & 9,04 & 7,85 & 9,08 & 7,78 & 8,08 & 8,76 & 7,67 & 8,38 & 8,13 & \\
\hline Total & 4570,1 & 4350,1 & 4261,7 & 3785,8 & 3753,3 & 3662,6 & 3286,3 & 3099,1 & 3156,4 & 3369,5 & 3187,3 & $-3,36 * * *$ \\
\hline$(\%)$ & 100 & 100 & 100 & 100 & 100 & 100 & 100 & 100 & 100 & 100 & 100 & \\
\hline \multicolumn{13}{|c|}{ Empregador } \\
\hline$\geq 0,1 \mathrm{a}<1$ ha & 7,7 & 7,7 & 9,6 & 6,4 & 15,7 & 11 & 23,8 & 9,5 & 9 & 10,9 & 8,5 & $2,53^{\mathrm{NS}}$ \\
\hline$(\%)$ & 1,47 & 1,52 & 1,97 & 1,69 & 3,6 & 2,75 & 8,27 & 3,46 & 3,92 & 4,54 & 3,33 & \\
\hline$\geq 1 \mathrm{a}<5$ ha & 74,7 & 57 & 59,4 & 50,7 & 64,8 & 52,2 & 30,3 & 35,1 & 27,7 & 18,7 & 35 & $-9,34 * * *$ \\
\hline$(\%)$ & 14,31 & 11,17 & 12,16 & 13,35 & 14,88 & 13,03 & 10,53 & 12,79 & 12,07 & 7,78 & 13,73 & \\
\hline$\geq 5 \mathrm{a}<10$ ha & 40,9 & 38,6 & 45,6 & 23,1 & 42,7 & 30,1 & 23,9 & 22,7 & 12,8 & 16,6 & 21 & $-8,63^{* * *}$ \\
\hline (\%) & 7,83 & 7,56 & 9,34 & 6,08 & 9,8 & 7,51 & 8,3 & 8,27 & 5,58 & 6,91 & 8,24 & \\
\hline$\geq 10 \mathrm{a}<50 \mathrm{ha}$ & 158,5 & 147,7 & 129,9 & 123,4 & 114,3 & 100 & 74,6 & 69,7 & 65,2 & 60,2 & 69,5 & $-8,75^{* * *}$ \\
\hline$(\%)$ & 30,36 & 28,94 & 26,6 & 32,49 & 26,24 & 24,96 & 25,92 & 25,39 & 28,41 & 25,05 & 27,27 & \\
\hline$\geq 50 \mathrm{a}<100 \mathrm{ha}$ & 61,7 & 68,2 & 65,9 & 59,1 & 54,7 & 61,7 & 40,8 & 32,6 & 30,9 & 32,8 & 33,7 & $-7,63^{* * *}$ \\
\hline (\%) & 11,82 & 13,36 & 13,5 & 15,56 & 12,56 & 15,4 & 14,18 & 11,88 & 13,46 & 13,65 & 13,22 & \\
\hline$\geq 100 \mathrm{a}<10.000$ ha & 178,6 & 191,1 & 177,9 & 117,1 & 143,4 & 145,6 & 94,4 & 104,9 & 83,9 & 101,1 & 87,2 & $-7,04 * * *$ \\
\hline$(\%)$ & 34,21 & 37,45 & 36,43 & 30,83 & 32,92 & 36,35 & 32,8 & 38,21 & 36,56 & 42,07 & 34,21 & \\
\hline Total & 522,1 & 510,3 & 488,3 & 379,8 & 435,6 & 400,6 & 287,8 & 274,5 & 229,5 & 240,3 & 254,9 & $-7,72^{\star \star *}$ \\
\hline$(\%)$ & 100 & 100 & 100 & 100 & 100 & 100 & 100 & 100 & 100 & 100 & 100 & \\
\hline \multicolumn{13}{|c|}{ Conta própria } \\
\hline$\geq 0,1 \mathrm{a}<1$ ha & 457,8 & 426,2 & 406,9 & 377,6 & 350,6 & 384,5 & 477,1 & 409,7 & 347,1 & 514,3 & 404,6 & $0,22^{\mathrm{NS}}$ \\
\hline$(\%)$ & 11,31 & 11,10 & 10,78 & 11,09 & 10,57 & 11,79 & 15,91 & 14,50 & 11,86 & 16,44 & 13,80 & \\
\hline$\geq 1 \mathrm{a}<5$ ha & 1419,5 & 1426,6 & 1387,3 & 1115 & 1182,5 & 1112,9 & 951,3 & 864,6 & 974,4 & 1015,9 & 972,6 & $-3,99 * * *$ \\
\hline$(\%)$ & 35,07 & 37,15 & 36,77 & 32,74 & 35,64 & 34,12 & 31,73 & 30,61 & 33,29 & 32,47 & 33,17 & \\
\hline$\geq 5 \mathrm{a}<10$ ha & 517,3 & 463,6 & 466,7 & 457,1 & 447,5 & 433,2 & 360,7 & 371,2 & 396,7 & 383,9 & 355,8 & $-2,99 * * *$ \\
\hline (\%) & 12,78 & 12,07 & 12,37 & 13,42 & 13,49 & 13,28 & 12,03 & 13,14 & 13,55 & 12,27 & 12,13 & \\
\hline$\geq 10 \mathrm{a}<50 \mathrm{ha}$ & 1180,6 & 1083,4 & 1047,7 & 1060 & 951,4 & 966,1 & 862,1 & 836 & 885,7 & 852,7 & 851,8 & $-2,91 * \star \star$ \\
\hline (\%) & 29,17 & 28,22 & 27,77 & 31,12 & 28,68 & 29,62 & 28,75 & 29,60 & 30,26 & 27,25 & 29,05 & \\
\hline$\geq 50 a<100$ ha & 255,3 & 236,8 & 257,4 & 216 & 188,2 & 226 & 176,1 & 176,4 & 164,9 & 181,1 & 175,8 & $-3,77^{* * *}$ \\
\hline$(\%)$ & 6,31 & 6,17 & 6,82 & 6,34 & 5,67 & 6,93 & 5,87 & 6,25 & 5,63 & 5,79 & 6,00 & \\
\hline$\geq 100 \mathrm{a}<10.000$ ha & 217,4 & 203,1 & 207,4 & 180,3 & 197,4 & 139,3 & 171,1 & 166,7 & 158,1 & 181,3 & 171,8 & $-2,11 * * *$ \\
\hline$(\%)$ & 5,37 & 5,29 & 5,50 & 5,29 & 5,95 & 4,27 & 5,71 & 5,90 & 5,40 & 5,79 & 5,86 & \\
\hline Total & 4047,9 & 3839,7 & 3773,4 & 3406 & 3317,6 & 3262 & 2998,4 & 2824,6 & 2926,9 & 3129,2 & 2932,4 & $-2,90 * \star *$ \\
\hline (\%) & 100 & 100 & 100 & 100 & 100 & 100 & 100 & 100 & 100 & 100 & 100 & \\
\hline
\end{tabular}

Fonte: elaborada a partir dos microdados da Pesquisa Nacional por Amostra de Domicílios (PNAD), do Instituto Brasileiro de Geografia e Estatística (IBGE). Notas: ${ }^{1} \geq 0,1$ a $<10.000$ ha. ${ }^{2}$ Taxa média de crescimento anual expressa em porcentagem. Corresponde à estimativa do coeficiente de uma regressão log-linear contra o tempo. Neste caso, o teste trevela a existência ou não de tendência nos dados; *** indica o nível de significância de 1\%; e NS indica a não significância. 
Em suma, os resultados estão em conformidade com os estudos de Hoffmann \& Ney (2010), que verificaram expressiva redução do número de empreendimentos agrícolas no Brasil. Essa tendência foi observada por esses autores de forma mais acentuada a partir de 1999, tornando-se acelerada a partir de 2004. Além disso, os autores perceberam que, no período de 1992 a 2008, em relação ao número total de empreendimentos agrícolas nas grandes regiões do país, a menor tendência de queda foi observada na região Sul. O mesmo aconteceu em outros países, como no caso dos Estados Unidos, onde também houve queda no número de empreendimentos rurais e um processo de concentração de terras agrícolas (Sumner, 2014).

A discussão sobre os empreendimentos agrícolas tem se tornado cada vez mais frequente na literatura global (Ney \& Hoffmann, 2008; Eastwood et al., 2010; Hazell et al., 2010; Deininger \& Byerlee, 2012; Masters et al., 2013; Adamopoulos \& Restuccia, 2014; Lowder et al., 2016), o que se deve à importância das unidades produtivas no desenvolvimento econômico e social, pois, além de ser o espaço em que se produz alimento, tendo grande relevância no abastecimento e segurança alimentar, elas têm impacto direto nas transformações sociais dentro e fora do campo, tais como a concentração fundiária e o êxodo rural.

O tamanho médio das propriedades agrícolas aumentou na América do Norte e na Europa entre 1950 a 1990, justificando a queda no número de empreendimentos agrícolas nessas localidades (Eastwood et al., 2010). Uma das causas para isso se deve à abundância de terra em alguns países da América Latina, Europa Oriental e Ásia Central (Deininger \& Byerlee, 2012). Outro fato é que o tamanho médio dos empreendimentos aumentou na maioria dos países de média renda e em quase todos os de alta renda (Lowder et al., 2016). A explicação para esse fenômeno se dá pela relação entre o tamanho do empreendimento e o custo de oportunidade do trabalho, pois, à medida que os salários não agrícolas aumentam, o tamanho dos estabelecimentos se amplia de forma a equalizar os rendimentos entre os setores da economia (Eastwood et al., 2010).

Com isso, o crescimento esperado na demanda por produtos agrícolas, como alimentos, rações ou insumos de outras indústrias (biocombustíveis), levou à redução no número e ao aumento do tamanho de grandes empreendimentos agropecuários. Segundo Deininger \& Byerlee (2012), essa tendência é notável na América Latina, na Europa Oriental, na África Subsaariana e no sudeste da Ásia. Para os autores, os fatores que há muito tempo sustentam essa expansão advêm das economias de escala nas plantações, distorções políticas e maior capacidade das grandes fazendas de lidar com as imperfeições dos mercados de financiamentos e de seguros. Todavia, o aumento do tamanho médio das propriedades agrícolas não é uma tendência geral no espaço e no tempo, visto que, entre 1970 e 2000, houve diminuição do tamanho médio das unidades produtivas em países considerados de baixa e média renda da África, Ásia e América Latina (Hazell et al., 2010; Eastwood et al., 2010; Masters et al., 2013; Lowder et al., 2016).

No caso do Brasil, Hoffmann e Ney (2010), com base nos dados dos Censos Agropecuários (1995-1996 e 2006) e da PNAD, analisaram a estrutura fundiária e constataram que, embora tenha ocorrido um aumento do número de empreendimentos agrícolas e uma queda na área média dos estabelecimentos e empreendimentos agrícolas, houve maior concentração de terras. Além disso, eles verificaram que todas as grandes regiões brasileiras apresentavam alta desigualdade na distribuição da posse da terra, o que pode ser verificado na proporção da área total agrícola ocupada pelos estabelecimentos com área $\geq 100$ ha - que representam. Estes, que representam somente $9,6 \%$ do total de estabelecimentos agrícolas no país e ocupam 78,6\% da área total dedicada à atividade agropecuária, enquanto os empreendimentos com área inferior a 10 ha, apesar de representarem mais de 50\% dos estabelecimentos, ocupam apenas 2,4\% da área total (Hoffmann \& Ney, 2010). 
Assim como os resultados de Hoffmann \& Ney (2010), os obtidos no presente estudo evidenciam que há um elevado número de empreendimentos agropecuários com áreas pequenas e um diminuto número daqueles que possuem áreas maiores. Tais constatações denotam a enorme desigualdade fundiária existente no Brasil, que afeta a oferta de empregos e de alimentos no país, e, por isso mesmo, precisam ser pautadas e consideradas no contexto das ações voltadas à segurança alimentar e nutricional e ao desenvolvimento rural e urbano, com destaque para a reforma agrária.

Cabe destacar que a dinâmica dos empreendimentos agrícolas também pode estar associada à demanda global por terra, especialmente considerando as tendências recentes ligadas ao ciclo de commodities. A demanda por terra se deve tanto pela busca da apropriação da renda produtiva gerada na agricultura como pelo investimento que ela representa, ou seja, como reserva de valor ou como meio de proteção contra a inflação, baixas taxas de juros e incertezas em torno da economia internacional. Por isso, a terra é considerada um ativo produtivo e financeiro que protege os agentes diante dos problemas inerentes aos ciclos econômicos (Oyhantçabal \& Narbondo, 2019). Portanto, é possível que a variação do número de empreendimentos agrícolas no Brasil esteja relacionada também com os ciclos econômicos.

Em relação à segurança alimentar e nutricional, a diversificação da produção de alimentos pode resultar em benefícios econômicos, sociais e ambientais para toda a sociedade brasileira, na medida em que favorece não só os habitantes do meio rural, mas também os do meio urbano, seja pelo potencial de aumentar a quantidade e a qualidade de alimentos ofertados, seja por possibilitar a amenização de problemas decorrentes do crescimento populacional das cidades.

\section{CONCLUSÕES}

As taxas médias de variação anual estimada por meio da distribuição das atividades mais frequentes nos empreendimentos de empregador e de conta própria no Brasil, segundo o estrato de área total, no período de 2004 a 2015, mostram redução na maioria das atividades, de forma mais acentuada para a cultura do arroz e para as lavouras temporárias. Já os empreendimentos ligados à produção mista e à silvicultura apresentaram as maiores taxas de crescimento.

Em relação à distribuição de empreendimentos de empregador e de conta própria, por estrato de área, o maior percentual de participação esteve no estrato de $\geq 1 \mathrm{a}<5 \mathrm{ha}$, com decréscimo no número de empreendimentos agrícolas da ordem de 3,3\% a.a. 0 estrato com o menor percentual de participação foi o de $\geq 50$ a $<100$ ha, que apresentou o maior decréscimo no número de empreendimentos (4,5\% a.a).

Em geral, o número de empreendimentos agrícolas está diminuindo a uma taxa de 3,4\% a.a. Entre 2004 e 2015 essa redução foi de aproximadamente 1.382 .700 empreendimentos agrícolas, sendo mais intenso na categoria empregador. As possíveis causas dessa redução se devem, em grande parte, pela mecanização, pelo avanço tecnológico no campo, pelo custo de oportunidade da produção de culturas mais comerciais, produzidas em larga escala, em relação àquelas ligadas à produção familiar, de pequena escala, e pela tendência mundial do aumento do tamanho médio dos empreendimentos agrícolas. Outras possíveis causas para essa redução podem estar relacionadas ao ciclo econômico do período em questão, que envolve o ciclo das commodities e as crises econômicas internacionais. Esses fatos podem impactar não somente a redução do número de empreendimentos agrícolas, mas também a concentração fundiária, a produção de alimentos nas áreas dos empreendimentos e a redução da PEA agrícola. Essas possíveis causas merecem estudos futuros para a sua validação. 
Vale destacar que a redução do número de empreendimentos agrícolas tem relevância para a segurança alimentar, a qual não se dá somente pelos volumes de produção de alimentos que deixam de ser produzidos, mas por afetar o autoconsumo e a renda das famílias que estavam a eles vinculadas, que dependiam deles e que desapareceram.

Nesse contexto, os resultados aqui apresentados podem e devem subsidiar, com maior objetividade, o delineamento de ações públicas voltadas a cada um dos setores da agropecuária e do Brasil.

\section{Referências}

Adamopoulos, T., \& Restuccia, D. (2014). The size distribution of farms and international productivity differences. The American Economic Review, 104(6), 1667-1697.

Anjos, F. S., Caldas, N. V., \& Hirai, W. G. (2009). A dimensão rural da insegurança alimentar: transformações nas práticas de autoconsumo entre famílias rurais do extremo sul gaúcho. Segurança Alimentar e Nutricional, 16(1), 1-17.

Artuzo, F. D., Foguesatto, C. R., Souza, A. R. L., \& Silva, L. X. (2018). Gestão de custos na produção de milho e soja. Revista Brasileira de Gestão de Negócios, 20(2), 273-294.

Balsadi, O. V., \& Del Grossi, M. E. (2016). Trabalho e emprego na agricultura brasileira um olhar para o período 2004-2014. Revista de Política Agrícola, 25(4), 82-96.

Bevilaqua, G. A. P., Antunes, I. R., Barbieri, R. L., Schwengber, J. E., Anjos e Silva, S. D., Leite, D. P., \& Cardoso, J. H. (2014). Agricultores guardiões de sementes e ampliação da agrobiodiversidade. Cadernos de Ciência \& Tecnologia, 31(1), 99-118.

Buainain, A. M., \& Dedecca, C. S. (2010). Mudanças e reiteração da heterogeneidade do mercado de trabalho agrícola. In J. Gasques, J. Vieira Filho \& Z. Navarro (Eds.), A agricultura brasileira: desempenho, desafios e perspectivas (pp. 123-156). Brasília: IPEA.

Deininger, K., \& Byerlee, D. (2012). The rise of large farms in land abundant countries: Do they have a future? World Development, 40(4), 701-714.

Del Grossi, M., \& Graziano da Silva, J. (2006). Mudanças recentes no mercado de trabalho rural. Parcerias Estratégicas, 11(22), 201-216.

Eastwood, R., Lipton, M., \& Newell, A. (2010). Farm size. In P. L. Pingali \& R. E. Evenson (Eds.), Handbook of agricultural economics (Vol. 4, pp. 3323-3397). Burlington: Academic Press.

Ferreira Filho, J. B. S., \& Vian, C. E. F. (2016). The evolving role of large and medium farms on Brazilian agriculture. Agricultural Economics, 47(S1), 215-225. http://dx.doi.org/10.1111/agec.12310

Ferreira, B., Balsadi, O. V., Freitas, R. E., \& Almeida, A. N. (2006). Ocupações agrícolas e não agrícolas: trajetória e rendimentos no meio rural brasileiro. In J. A. De Negri, F. De Negri \& D. Coelho (Eds.), Tecnologia, exportação e emprego (pp. 445-488). Brasília: IPEA.

Fischer, A., Surdi, A. P., Santos Junior, S., \& Winck, C. A. (2015). A silvicultura madeireira na Secretaria e Desenvolvimento Regional de Joaçaba. Desenvolvimento em Questão, 29(13), 225-256.

Fuentes-Llanillo, R., Del Grossi, M. E., Santos, F. O., Munhos, P. D., \& Guimarães, M. F. (2006). Regionalização da agricultura do Estado do Paraná, Brasil. Ciência Rural, 36(1), 120-127. http://dx.doi.org/10.1590/S0103-84782006000100018

Grisa, C., \& Schneider, S. (2008). "Plantar pro gasto": a importância do autoconsumo entre famílias de agricultores do Rio Grande do Sul. Revista de Extensão Rural, 02(2), 481-515. http://dx.doi.org/10.1590/S0103-20032008000200008 
Hazell, P., Poulton, C., Wiggins, S., \& Dorward, A. (2010). The future of small farms: Trajectories and policy priorities. World Development, 38(10), 1349-1361. http://dx.doi.org/10.1016/j. worlddev.2009.06.012

Helfand, S. M., Pereira, V. F., \& Soares, W. L. (2014). Pequenos e médios produtores na agricultura brasileira: situação atual e perspectivas. In A. M. Buainain, E. Alves, J. M. Silveira \& Z. Navarro (Eds.), O mundo rural no Brasil do século 21: a formação de um novo padrão agrário e agrícola (pp. 533-557). Brasília: Embrapa.

Hoffmann, R. (2011). Distribuição da renda agrícola e sua contribuição para a desigualdade de renda no Brasil. Revista de Política Agrícola, 20(2), 5-22.

Hoffmann, R., \& Ney, M. G. (2010). Estrutura fundiária e propriedade agrícola no Brasil: grandes regiões e unidades da federação. Brasília: Ministério do Desenvolvimento Agrário.

Instituto Brasileiro de Geografia e Estatística - IBGE. (2019). Censo agropecuário: resultados definitivos 2017. Rio de Janeiro: IBGE.

Instituto Brasileiro de Geografia e Estatística - IBGE. (2020). Pesquisa de orçamentos familiares 2017-2018: análise do consumo alimentar pessoal no Brasil. Rio de Janeiro: IBGE.

Laurenti, A. C., Pellini, T., \& Telles, T. S. (2015). Evolução da ocupação e do rendimento das pessoas no espaço rural brasileiro no período de 2001 a 2009. Revista de Economia e Sociologia Rural, 54(2), 321-342. http://dx.doi.org/10.1590/1234-56781806-9479005302008

Lowder, S. K., Skoet, J., \& Raney, T. (2016). The number, size, and distribution of farms, smallholder farms, and family farms worldwide. World Development, 87, 16-29. http:// dx.doi.org/10.1016/j.worlddev.2015.10.041

Maia, A. G., \& Buainain, A. M. (2015). O novo mapa da população rural brasileira. Confins, 25, 1-26.

Maia, A. G., \& Sakamoto, C. S. (2014). A nova configuração do mercado de trabalho agrícola brasileiro. In A. M. Buainain, E. Alves, J. M. Silveira \& Z. Navarro (Eds.), O mundo rural no Brasil do século 21: a formação de um novo padrão agrário e agrícola (pp. 591-619). Brasília: Embrapa.

Masters, W. A., Djurfeldt, A. A., De Haan, C., Hazell, P., Jayne, T., Jirström, M., \& Reardon, T. (2013). Urbanization and farm size in Asia and Africa: Implications for food security and agricultural research. Global Food Security, 2(3), 156-165. http://dx.doi.org/10.1016/j.gfs.2013.07.002

Mattei, L. (2015). Emprego agrícola: cenários e tendências. Estudos Avançados, 29(85), 35-52. http://dx.doi.org/10.1590/S0103-40142015008500004

Navarro, Z. S., \& Campos, S. K. (2014). A "pequena produção rural" no Brasil e as tendências do desenvolvimento agrário brasileiro. Revista de Extensão e Estudos Rurais, 3(1), 25-92.

Neder, H. D. (2008). Estrutura do mercado de trabalho agrícola no Brasil: uma análise descritiva da evolução de suas categorias entre 1995 e 2006. In A. M. Buainain \& C. Dedecca (Eds.), Trabalho e emprego na agricultura brasileira (pp. 156-182). Brasília: IICA.

Ney, M. G., \& Hoffmann, R. (2003). Desigualdade de renda na agricultura: o efeito da posse da terra. Economía, 4(1), 113-152.

Ney, M. G., \& Hoffmann, R. (2008). A contribuição das atividades agrícolas e não-agrícolas para a desigualdade de renda no Brasil rural. Economia Aplicada, 12(3), 365-393. http://dx.doi. org/10.1590/S1413-80502008000300002

Oyhantçabal, G., \& Narbondo, I. (2019). Land grabbing in Uruguay: New forms of land concentration. Canadian Journal of Development Studies, 40(2), 201-219. http://dx.doi. org/10.1080/02255189.2018.1524749 
Proni, M. W. (2010). Mapeamento do trabalho agrícola no Brasil. In A. Moretto, J. D. Krein, M. Pochmann \& J. Macambira (Eds.), Economia, desenvolvimento regional e mercado de trabalho do Brasil (pp. 139-176). Fortaleza: Instituto de Desenvolvimento do Trabalho, Banco do Nordeste do Brasil, Centro de Estudos Sindicais e de Economia do Trabalho.

Proni, M. W., \& Garrido, F. L. (2005). Agricultura, desigualdade regional e trabalho no Brasil. Revista da $A B E T, 5(1), 219-247$.

Rocha, C., Burlandy, L., \& Maluf, R. (2012). Small farms and sustainable rural development for food security: The Brazilian experience. Development Southern Africa, 29(4), 519-529. http://dx.doi.org/10.1080/0376835X.2012.715438

Sakamoto, C. S., \& Maia, A. G. (2012). Dinâmica do mercado de trabalho agrícola e impactos sobre a distribuição de rendimentos nos anos 2000. Revista da ABET, 11(2), 11-31.

Santos, M. (2005). A urbanização brasileira (5. ed.). São Paulo: Edusp.

Sauer, S., \& Leite, S. P. (2012). Expansão agrícola, preços e apropriação de terra por estrangeiros no Brasil. Revista de Economia e Sociologia Rural, 50(3), 503-524. http://dx.doi.org/10.1590/ S0103-20032012000300007

Staduto, J. A. R., Nascimento, C. A., \& Souza, M. (2013). Ocupações e renda das mulheres e homens no rural do estado do Paraná, Brasil: uma perspectiva de gênero. Cuadernos de Desarrollo Rural, 10(72), 91-115.

Sumner, D. A. (2014). American farms keep growing: Size, productivity, and policy. The Journal of Economic Perspectives, 28(1), 147-166. http://dx.doi.org/10.1257/jep.28.1.147

Telles, T. S., Costa, G. V., Bacchi, M. D., \& Laurenti, A. C. (2017). Evolução da população rural ocupada nas Grandes Regiões do Brasil entre 2001 e 2009. Interações, 18(1), 17-26. http:// dx.doi.org/10.20435/1984-042X-2017-v.18-n.1(02)

Telles, T. S., Costa, G. V., Castro, G. H. L., Bachi, M. D., \& Laurenti, A. C. (2019). Decrease in the number of farms in the State of Paraná, Brazil. Semina: Ciências Agrárias, 40(1), 127-138. http://dx.doi.org/10.5433/1679-0359.2019v40n1p127

Vieira Filho, J. E. R. (2013). Heterogeneidad estructural de la agricultura familiar en el Brasil. Revista Cepal, 111(111), 103-121. http://dx.doi.org/10.18356/7248f152-es 